\title{
Effect of Weight on the Resonant Tuning of Energy Harvesting Devices Using Giant Magnetostrictive Materials
}

\author{
Kotaro Mori $^{1, *(\mathbb{D})}$, Tadashi Horibe ${ }^{1}$ and Shigekazu Ishikawa ${ }^{2}$ \\ 1 Department of Mechanical Engineering, College of Engineering, Ibaraki University, \\ 4-12-1 Nakanarusawa-cho, Hitachi 316-8511, Japan; tadashi.horibe.mech@vc.ibaraki.ac.jp \\ 2 Hitachi Power Solutions Co., Ltd., 3-2-2 Saiwai-cho, Hitachi 317-0073, Japan; \\ shigekazu.ishikawa.fs@hitachi.com \\ * Correspondence: kotaro.mori.1@vc.ibaraki.ac.jp; Tel.: +81-294-38-5043
}

Received: 23 March 2018; Accepted: 7 April 2018; Published: 10 April 2018

check for updates

\begin{abstract}
This study deals with the numerical and experimental study of the effect of weight on the resonant tuning and energy harvesting characteristics of energy harvesting devices using giant magnetostrictive materials. The energy harvesting device is made in a cantilever shape using a thin Terfenol-D layer, stainless steel (SUS) layer and a movable proof mass, among other things. In this study, two types of movable proof mass were prepared, and the device was designed to adjust its own resonant frequency automatically to match external vibration frequency in real time. Three-dimensional finite element analysis (FEA) was performed, and the resonant frequency, tip displacement, and output voltage in the devices were predicted and measured, and the simulation and experiment results were compared. The effects of the weight of the proof mass on self-tuning ability and time-varying behavior were then considered in particular.
\end{abstract}

Keywords: cantilever; magnetostrictive material; energy harvesting; self-tuning

\section{Introduction}

Magnetostrictive materials show elongation or contraction under external magnetic fields, and the magnetization changes in connection with applied forces [1,2]. Until now, magnetostrictive materials have been mainly used as sensors and actuators because of their suitable properties, such as high energy density, quick response and the possibility of remote operation. Recently, magnetostrictive $\mathrm{Fe}-\mathrm{Co}$. alloys have gained attention owing to their low cost and abundance compared to existing magnetostrictive materials, and the range of uses of magnetostrictive materials is expected to expand [3-5]. In particular, the use of these materials for energy harvesting has gained the interest of researchers, and some results in this regard have been reported [6,7].

Energy harvesting is defined as the conversion of the ambient energy present in the environment into usable electrical energy and is expected to be employed as the power source for devices, such as IoT (Internet of Things) devices and sensors [8,9]. In particular, devices for vibration energy harvesting are anticipated to be a substitute for battery-powered systems. Moreover, their lifetime is generally several times that of a battery, and they are a tempting substitute in vibration-rich environments. However, the primary issue in vibration energy harvesting is that the best performance of a generator is usually limited to excitation at its fundamental resonance frequency, and usually, ambient vibrations comprise several frequency components [10]. If the resonant frequency of devices deviates slightly from the frequency of the ambient vibration, the power output is drastically reduced. Thus, a major challenge for the accomplishment of energy harvesting using resonance is widening the range of the 
resonant frequency of the device. Over the past few years, due to the importance of resonant frequency matching to allow the generation of power from ambient vibrations, researchers have adopted various techniques to tackle this $[11,12]$. Firoozy et al. investigated the mechanical behavior of a broadband energy harvesting system comprising a unimorph piezoelectric cantilever beam with a tip magnet and two external permanent magnets [13]. Miller et al. considered the beam-mass resonator system, which consists of a fixed-fixed beam and a mass that is able to slide along the beam and showed that these resonators enable adjustment to varying input frequencies and thereby, increase the energy harvested over time [14]. A previous study demonstrated that the output voltage increases with the sliding of the movable proof mass, and the tendency of this movement depends on the driving frequency [15].

In this paper, we discuss the influence of weight on the self-tuning and power output tendencies of a magnetostrictive energy harvesting device. We adopted a combined numerical and experimental approach in this study. The energy harvesting device constituted a perforated cantilever beam and a movable proof mass installed in the slit hole of the device. Finite element analysis (FEA) was executed to forecast the resonant frequency, tip displacement, and output voltage in the device. The resonant frequency, tip displacement, output voltage, and self-tuning behavior were also estimated, and the obtained results were then compared with numerical simulation results. Then, we determined the influence of the weight of the movable proof mass based on the inclination of the proof mass to move and the principle that the direction of sliding of the proof mass changes with the input frequency.

\section{Analysis}

\subsection{Basic Equation}

Consider the orthogonal coordinate system with axes $x_{1}, x_{2}$ and $x_{3}$. The basic equations for magnetostrictive materials are as follows [16]:

$$
\begin{gathered}
\sigma_{j i, j}=\rho u_{i, t t}+c u_{i, t} \\
B_{i, i}=0
\end{gathered}
$$

where $\sigma_{i j}$ and $B_{i}$ are the stress and magnetic flux density, respectively; $u_{i}$ is the displacement; and $\rho$ and $c$ are the mass density and the damping coefficient, respectively. A comma followed by an index denotes partial differentiation of the space coordinate, $x_{i}$, or the time, $t$. We introduced the summation convention for repeated tensor indices. The constitutive equations can be noted by the following equations [2,17]:

$$
\begin{gathered}
\varepsilon_{i j}=s_{i j k l}^{H} \sigma_{k l}+d_{k i j}^{m} H_{k} \\
B_{i}=d_{i k l}^{m} \sigma_{k l}+\mu_{i k} H_{k}
\end{gathered}
$$

where $\varepsilon_{i j}$ and $H_{i}$ are the strain and the magnetic field intensity; $s^{H}{ }_{i j k l}, d^{m}{ }_{k i j}, \mu_{i j}$ are the elastic compliance for a constant magnetic field, the piezo-magnetic constant and the magnetic permittivity. The valid symmetry conditions for the material constants are as follows:

$$
s_{i j k l}^{H}=s_{j i k l}^{H}=s_{i j l k}^{H}=s_{k l i j}^{H}, d_{k i j}^{m}=d_{k j i}^{m}, \mu_{i j}=\mu_{j i}
$$

The strain and magnetic field intensity are related to the displacement and magnetic potential $(\phi)$ by the following relationship:

$$
\begin{gathered}
\varepsilon_{i j}=\frac{1}{2}\left(u_{j, i}+u_{i, j}\right) \\
H_{i}=\phi_{i}
\end{gathered}
$$




\subsection{Model}

The energy harvesting device used for this study comprised a cantilever with a slit hole (Figure 1). Let the coordinate axes, $x=x_{1}$ and $z=x_{3}$, be chosen such that they coincide with the center of the thickness direction of the device; the $y=x_{2}$-axis is perpendicular to this plane. The origin of the coordinate system is located at the center of the fixed end of the device. The Terfenol-D layer is magnetized in the $z$-direction. The Terfenol-D, neodymium, and tungsten layers are sandwiched between two perforated stainless steel (SUS) layers. Here, $l, w$ and $h$ are the length, width and thickness, respectively, and the subscripts, $T, n, t$ and $s$ indicate the Terfenol-D, neodymium, tungsten and SUS layers, respectively. A slit hole (length $l_{h}$ and width $w_{h}$ ) was created on the SUS layer at a distance, $l_{i}$, from the neodymium layer. Let us now consider three cases of mass position and two mass types, as shown in Figure 2 (Cases 1-3 and Types 1 and 2). The imposed base excitation is applied by the displacement, $u_{y 0} \exp (i \omega t)$, of the fixed end ( $z=0$ plane), where $u_{y 0}$ is the amplitude of the applied displacement and $\omega$ is the angular frequency. The damping ratio determined from the experiments was adopted in the model. First, we calculated the tip displacement using FEA to gain the resonant frequency of each case and type. Then, we performed FEA for the induced magnetic field to obtain the output voltage. The output voltage was calculated using the induced magnetic field by following Faraday's law:

$$
V_{\text {out }}=-N w_{T} h_{T} \frac{d B_{z}}{d t}
$$

where $N$ is the turn number of a search coil; $B_{z}$ is the $z$-component of magnetic induction; and $t$ is the time. The constitutive equations for magnetostrictive materials are mathematically equivalent to those for piezoelectric materials. Therefore, coupled-field solid elements in ANSYS were used in the analysis. Only half of the device model was fabricated. In total, 7080 nodes and 15,161 elements and 12,285 nodes and 18,234 elements were adopted for Case 1 and Cases 2 and 3, respectively (there was no difference in the number of elements by type). The finite element calculations were performed by correcting the program with routines developed in our past work [15], and mesh sensitivity was established-the mesh was fine enough.

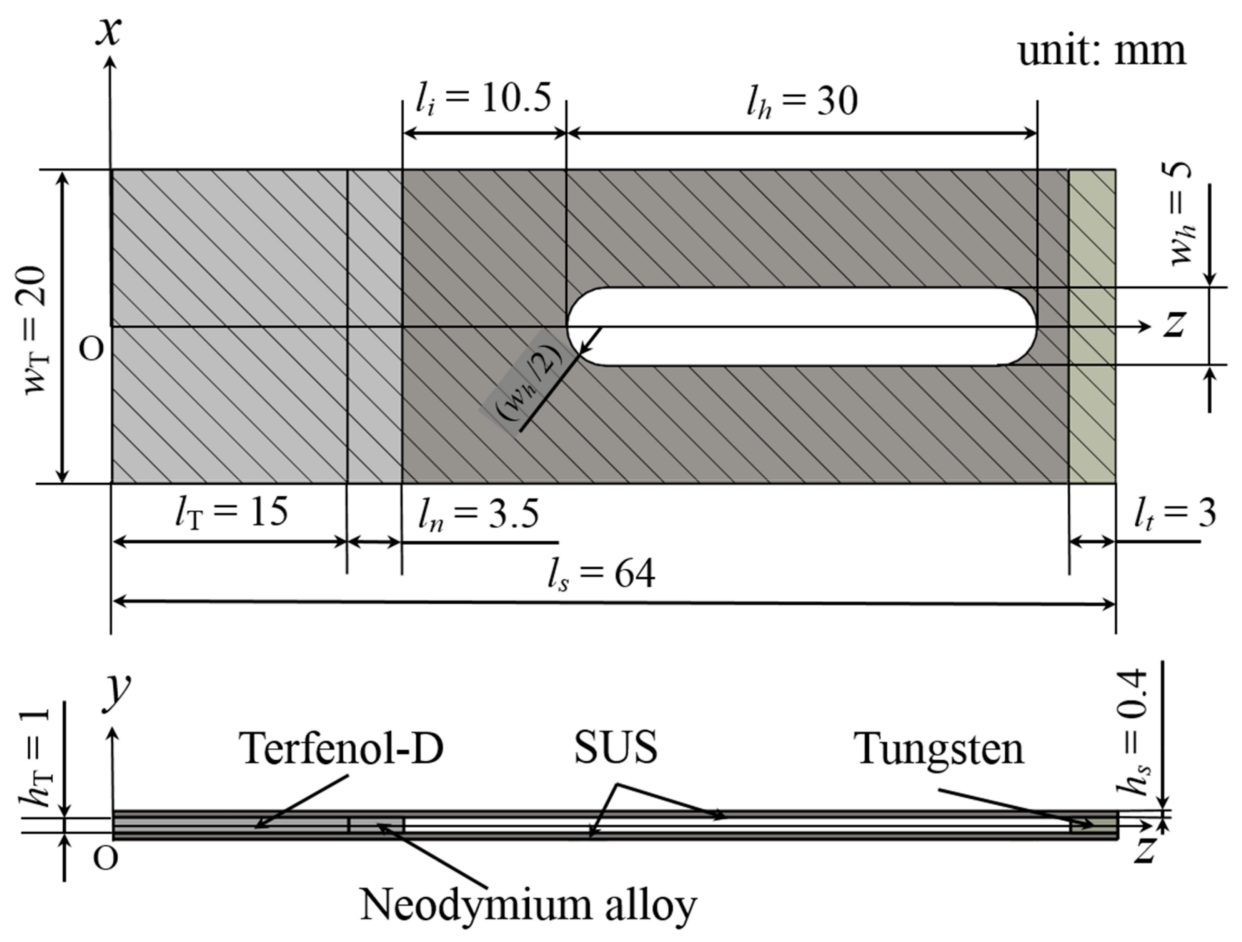

Figure 1. Illustration of the used energy harvesting device. 

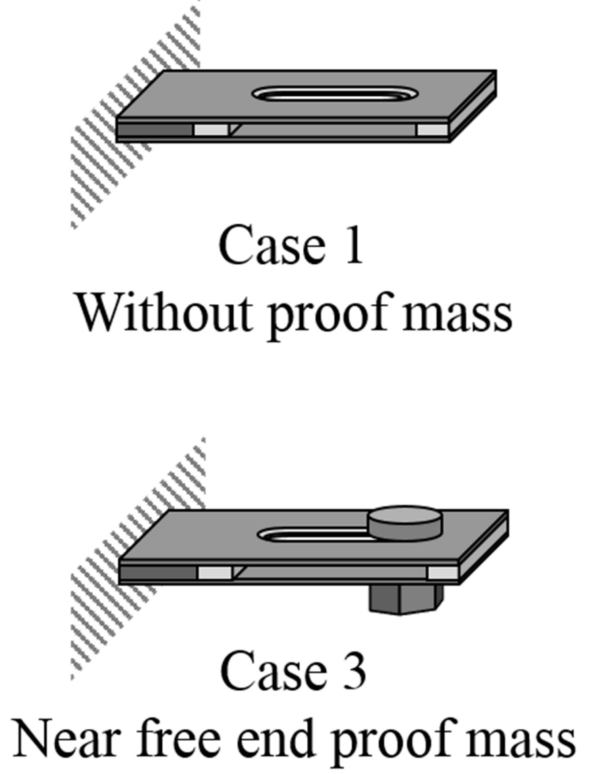

\section{Proof mass Type 1 : Tungsten}

Type 2 : Steel
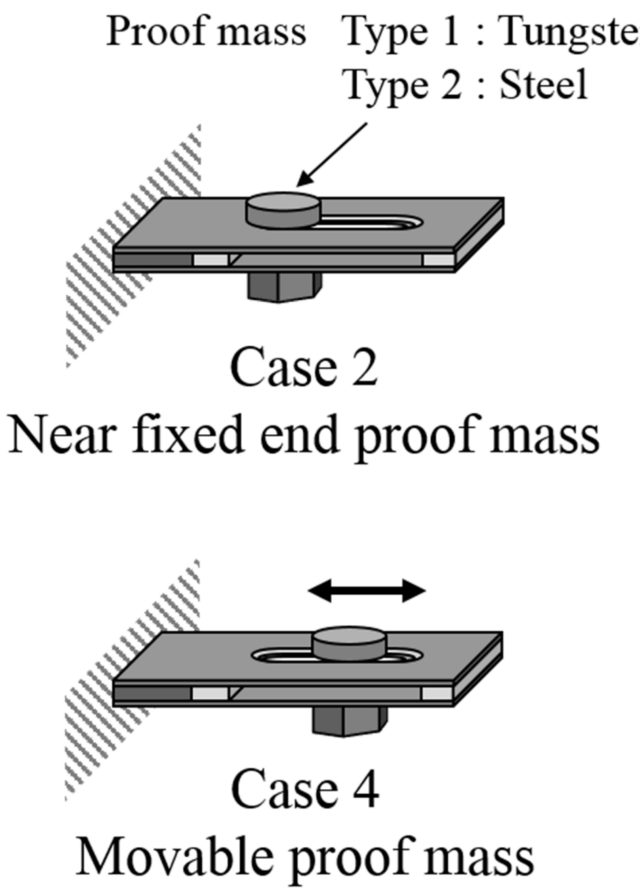

Figure 2. Schematic of a device with a proof mass.

\section{Experiments}

The energy harvesting device was constructed by sliding the Terfenol-D, neodymium, and tungsten layers between two perforated SUS layers, as shown in Figure 1. The dimensions of the Terfenol-D layer were as follows: length $l_{T}=15 \mathrm{~mm}$, width $w_{T}=20 \mathrm{~mm}$, and thickness $h_{T}=1 \mathrm{~mm}$. The dimensions of the SUS layer were as follows: length $l_{s}=64 \mathrm{~mm}$, width $w_{s}=20 \mathrm{~mm}$, and thickness $h_{s}=0.4 \mathrm{~mm}$. The lengths of the neodymium and tungsten layers were $l_{n}=3.5 \mathrm{~mm}$ and $l_{t}=3 \mathrm{~mm}$, respectively. The Terfenol-D, neodymium, and tungsten layers were perfectly glued between two SUS layers using epoxy. The gap between the neodymium and the slit hole was $l_{i}=10.5 \mathrm{~mm}$, and the slit hole $\left(l_{h}=30 \mathrm{~mm}, w_{h}=5 \mathrm{~mm}\right)$ existed at the center of the SUS layer $\left(\right.$ at $\left(l_{T}+l_{n}+l_{i}+l_{h} / 2\right)=44 \mathrm{~mm}$ from the fixed end). We considered four cases of mass position (Cases 1-4) and two mass types (Types 1 and 2), as shown in Figure 2. The masses of Types 1 and 2 were made of tungsten and steel. Tables 1 and 2 specify the materials' properties. The movable proof mass was deployed in the slit hole, and it was tightened at the corner on the free-end side or the fixed-end side of the hole of the device (Cases 2 and 3 , respectively).

First, we measured the tip displacement $\left(u_{y}\right)$ for the device using a laser displacement meter (LK-G30; Keyence Corporation, Osaka, Japan). Sinusoidal vibration was generated by the following equipment: a function generator (DF1905; NF Corporation, Yokohama, Japan), a vibration shaker (ET-132; Labworks Inc., Portland, OR, USA), and an amplifier (PA-151; Labworks Inc.). The specimen was mounted on the shaker and vibrations were applied. The input frequency, $f=\omega / 2 \pi$, was altered between 10 and $200 \mathrm{~Hz}$ at intervals of $10 \mathrm{~Hz}$ (except near the resonant frequency, around which $1 \mathrm{~Hz}$ intervals were employed). At each frequency, the generator amplitude was adjusted to an acceleration of $a=u_{y 0} \omega^{2}=1 \mathrm{~g}$.

Table 1. Material properties of Terfenol-D $[2,18]$.

\begin{tabular}{|c|c|c|c|c|c|c|c|c|c|c|c|}
\hline & \multicolumn{5}{|c|}{ Elastic Compliance $\left(\times 10^{-12} \mathrm{~m}^{2} / \mathrm{N}\right)$} & \multicolumn{3}{|c|}{$\begin{array}{c}\text { Piezo-Magnetic } \\
\text { Constant }\left(\times 10^{-9} \mathrm{~m} / \mathrm{A}\right)\end{array}$} & \multicolumn{2}{|c|}{$\begin{array}{l}\text { Magnetic Permittivity } \\
\left(\times 10^{-6} \mathrm{H} / \mathrm{m}\right)\end{array}$} & \multirow[t]{2}{*}{$\begin{array}{l}\text { Density } \\
\left(\mathrm{kg} / \mathrm{m}^{3}\right)\end{array}$} \\
\hline Terfenol-D & $\begin{array}{l}s^{H} 11 \\
17.9\end{array}$ & $\begin{array}{l}s^{H}{ }_{33} \\
17.9\end{array}$ & $\begin{array}{l}s^{H} 44 \\
26.3\end{array}$ & $\begin{array}{l}s^{H} 12 \\
-5.88\end{array}$ & $\begin{array}{l}s^{H} 13 \\
-5.88\end{array}$ & $\begin{array}{l}d^{m} 31 \\
-5.3\end{array}$ & $\begin{array}{c}d^{m} 33 \\
11\end{array}$ & $\begin{array}{l}d^{m} 15 \\
28\end{array}$ & $\begin{array}{c}T_{11} \\
36.1\end{array}$ & $\begin{array}{c}T_{33} \\
13.7\end{array}$ & \\
\hline
\end{tabular}


Table 2. Material properties.

\begin{tabular}{cccc}
\hline & Density $\mathbf{( k g / \mathbf { m } ^ { \mathbf { 3 } } )}$ & Poisson's Ratio (-) & Young's Modulus (GPa) \\
\hline Stainless Steel & 7930 & 0.3 & 193 \\
Neodymium magnet & 7500 & 0.3 & 170 \\
Tungsten & 19,000 & 0.28 & 190 \\
\hline
\end{tabular}

Next, the output voltage $\left(V_{\text {out }}\right)$ of the device was measured using a search coil and a wave logger (NR-600; Keyence Corporation, Osaka, Japan) (see Figure 3). The coil had a rectangular cross section with dimensions $22 \times 2.5 \mathrm{~mm}^{2}$ and a length of $20 \mathrm{~mm}$. It was wound using an $80 \mu \mathrm{m}$ diameter-enameled copper wire and had 2300 turns. We removed the constraint of the proof mass, enabling mobility of the mass (Case 4), and then measured the time-varying output voltage, $V_{\text {out }}$. The movable proof mass could freely slide within the slit hole, and the self-tuning behavior was examined under a high-speed microscope (VW-9000; Keyence Corporation, Osaka, Japan).

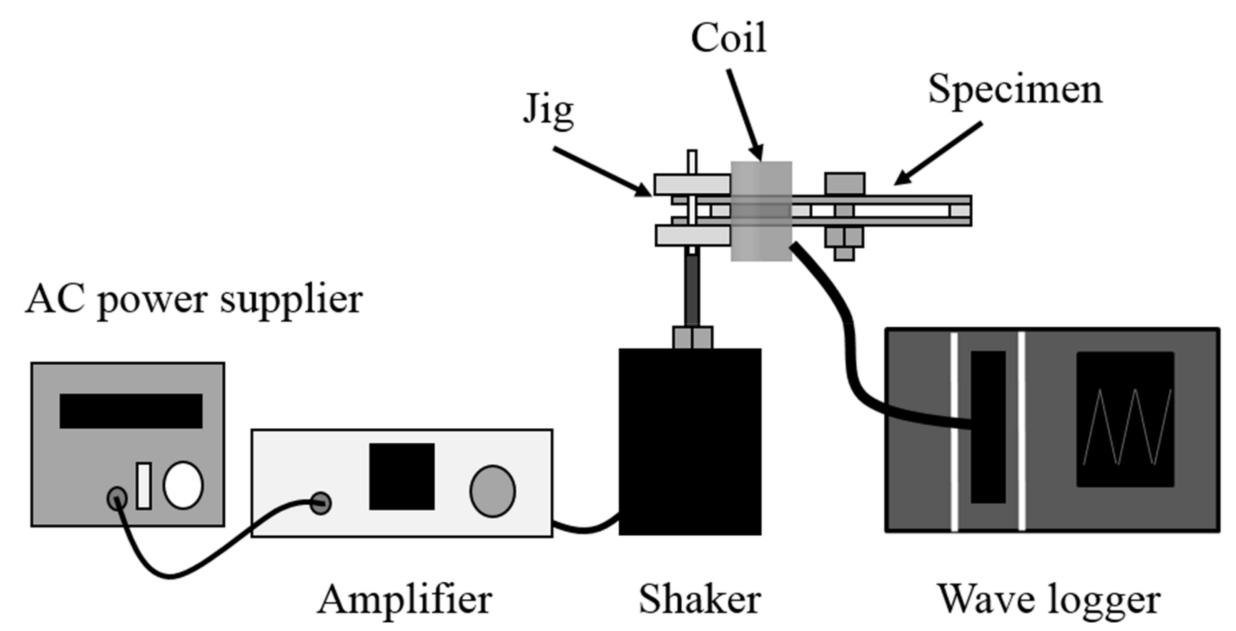

Figure 3. Experimental setup for measuring the output voltage.

\section{Results and Discussion}

We first discuss the results of Cases 1,2, and 3. Figure 4 shows the normalized displacement, $u_{y} / u_{y 0}$, as a function of frequency $(f)$ for energy harvesting device Types 1 and 2 . Here, $u_{y 0}$ is the displacement of the shaker. The lines and plots stand for the results of the FEA and experiment, respectively. Here, the lines are the results pertaining to the damping ratio obtained using the fast Fourier transform (FFT) analyzer (CF-7200; Ono Sokki Corporation, Yokohama, Japan) [15]. The damping ratios $(\zeta)$ of Cases 1,2 , and 3 of Type 1 (Type 2 ) were $0.0311,0.0374$ (0.0364), and 0.0225 (0.0252), respectively. The measured resonant frequencies of Cases 1, 2, and 3 of Type 1 were approximately 172,155 , and $101 \mathrm{~Hz}$, respectively, and the calculated resonant frequencies were approximately 194, 181 and $105 \mathrm{~Hz}$, respectively. The measured resonant frequencies for Cases 2 and 3 of Type 2 were approximately 167 and $129 \mathrm{~Hz}$, and the calculated resonant frequencies were approximately 195 and $145 \mathrm{~Hz}$, respectively. In Types 1 and 2, a reduction in resonant frequency was observed because of the existence of the proof mass, and the resonant frequency shift with change in the location of the proof mass. The results for Type 1 indicate an agreement between the experiment and analysis compared to the results of Type 2. Figure 5 shows the output voltage $\left(V_{\text {out }}\right)$ as a function of frequency $(f)$ for energy harvesting devices Types 1 and 2 under the open-circuit condition, as obtained from the FEA and experiment. The maximum output voltages for Cases 1, 2, and 3 of Type 1 (Type 2) were approximately 17.2, 13.9 (14.0), and $21.1(22.2) \mathrm{mV}$, respectively. The output voltage and displacement noted analogous tendencies with regard to the resonant frequency. 

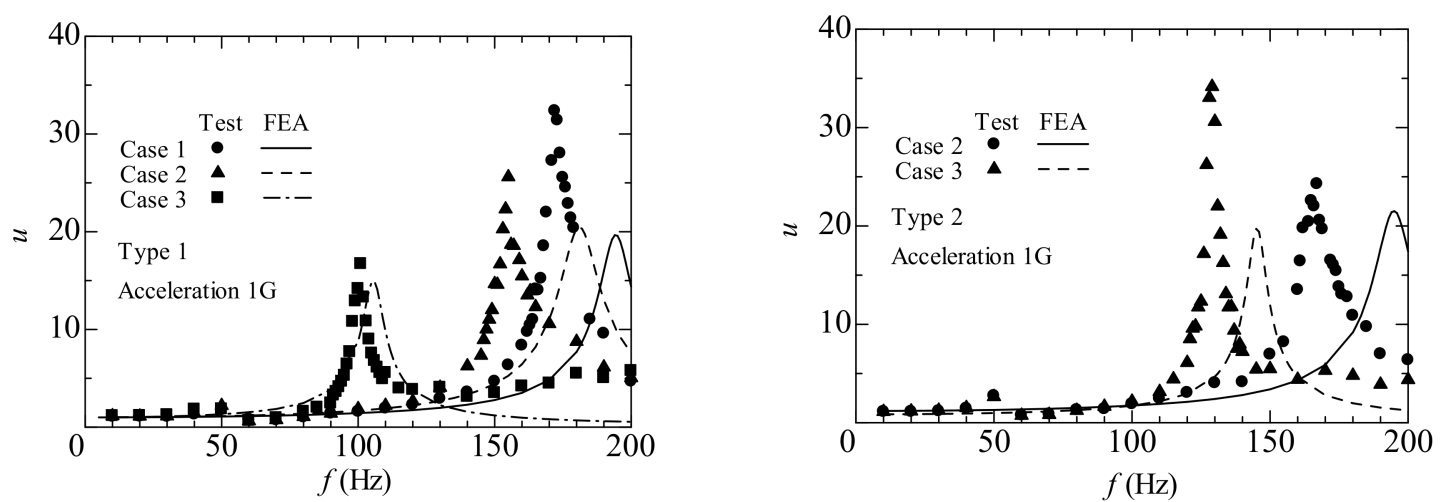

Figure 4. Normalized displacement versus frequency for the energy harvesting devices (Types 1 and 2).
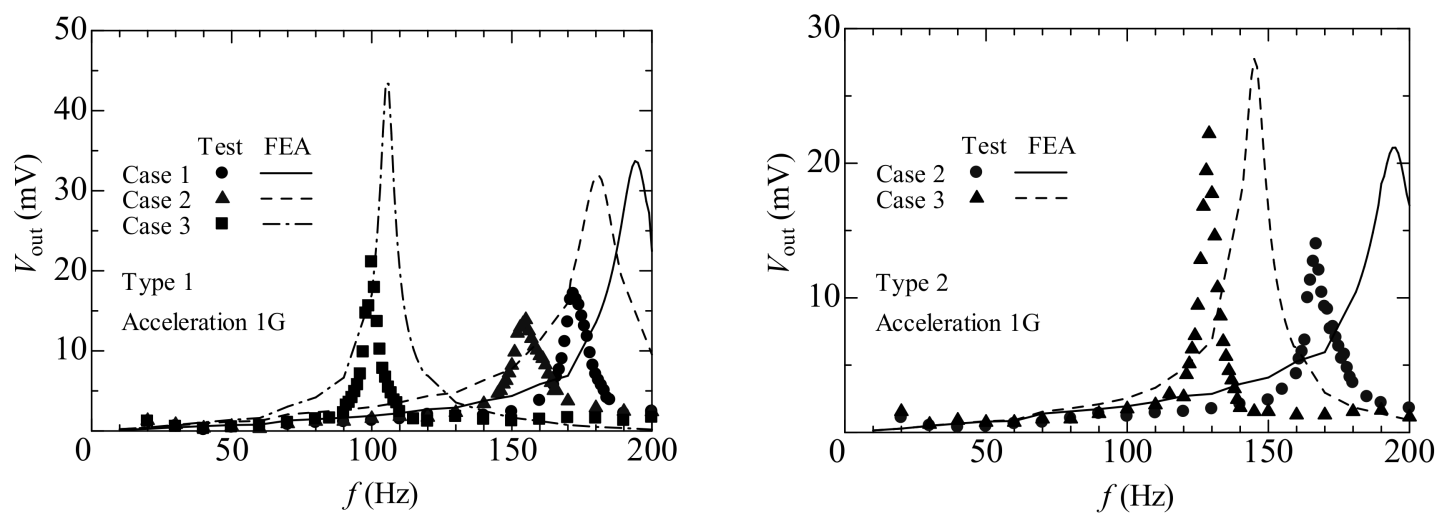

Figure 5. Output voltage versus frequency for the energy harvesting devices (Types 1 and 2).

Next, the results of Case 4 are presented. Table 3 classifies the tendency for proof mass movement corresponding to each frequency and type of weight. We estimated three starting positions: the fixed-end side $(z=32 \mathrm{~mm})$, the free-end side $(z=56 \mathrm{~mm})$, and the center of the hole $(z=45 \mathrm{~mm})$. Types 1 and 2 both demonstrated that the tendency for proof mass movement reverses with $50 \mathrm{~Hz}$ as the border. At frequencies lower than $50 \mathrm{~Hz}$, the proof mass slid from the free-end towards the fixed-end. However, at frequencies exceeding $50 \mathrm{~Hz}$, the proof mass types demonstrated different movement tendencies. In Type 1, the proof mass moved from the fixed-end towards the free-end at frequencies exceeding $60 \mathrm{~Hz}$. Further, at frequencies above $140 \mathrm{~Hz}$, the proof mass stopped on the way. Figure 6 shows the output voltages $\left(V_{\text {out }}\right)$ of Type 1 and Type 2 versus time $(t)$ for the energy harvesting device with the movable proof mass at $f=90 \mathrm{~Hz}$ (the starting position is fixed-end side). The output voltage increased with proof mass movement regardless of proof mass type, staying position and input frequency, and showed a similar waveform to Figure 6 (not shown here). In addition, the output voltage amplitude in Case 4 was more than 10 times that in Cases 1,2, and 3. Nevertheless, the increase in voltage associated with the movement of the proof mass of Type 1 was larger than that observed for Type 2. This difference is attributed to the difference in weight; in other words, the vibration of the heavier proof mass resulted in a larger force on the magnetostrictive layer. In addition, it is interesting to note that the output voltage showed a tendency similar to that seen in Figure 6 when the proof mass moved in the opposite direction. In order to clarify the capability of increasing the output voltage through self-tuning, we investigated the physical phenomenon of proof mass movement with different external frequencies. 

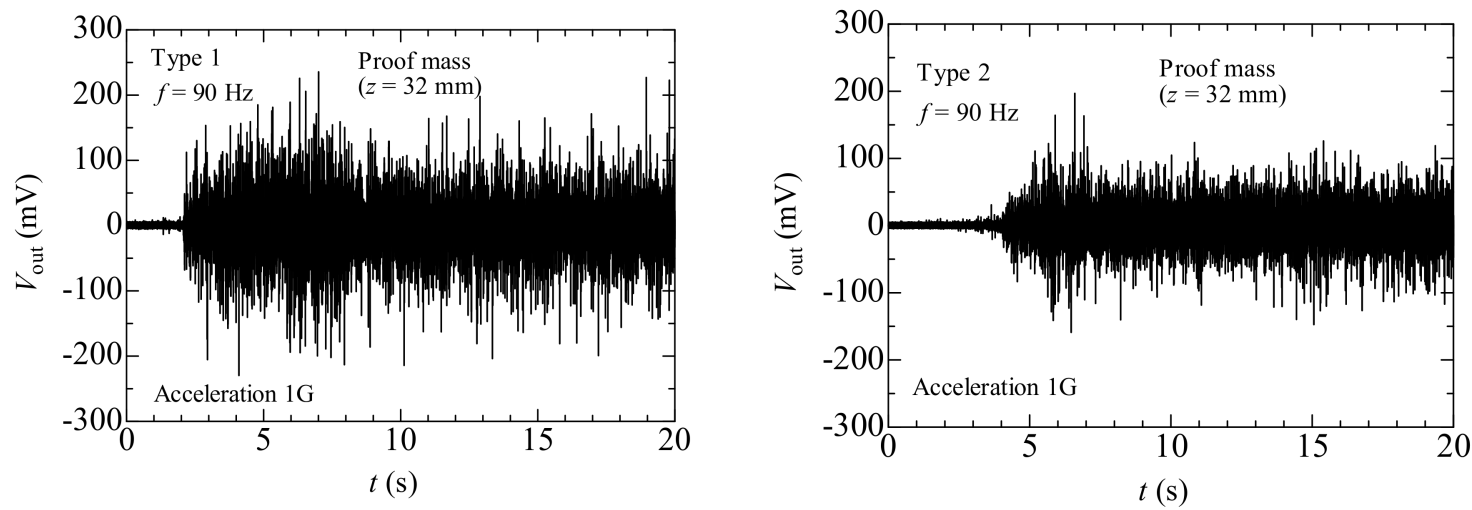

Figure 6. Output voltage versus time for the energy harvesting device with the proof mass $(f=90 \mathrm{~Hz}$, Types 1 and 2).

Table 3. Movement of the proof mass corresponding to input frequency.

\begin{tabular}{|c|c|c|c|c|c|c|}
\hline \multirow[b]{3}{*}{$f(\mathrm{~Hz})$} & \multicolumn{6}{|c|}{ Starting Position } \\
\hline & \multicolumn{2}{|c|}{$\begin{array}{l}\text { Fixed-End Side } \\
\quad(z=32 \mathrm{~mm})\end{array}$} & \multicolumn{2}{|c|}{$\begin{array}{l}\text { Free-End Side } \\
\quad(z=32 \mathrm{~mm})\end{array}$} & \multicolumn{2}{|c|}{$\begin{array}{c}\text { Middle } \\
(z=44 \mathrm{~mm})\end{array}$} \\
\hline & Type 1 & Type 2 & Type 1 & Type 2 & Type 1 & Type 2 \\
\hline 10 & $\times$ & $\times$ & 0 & $\times$ & 0 & $\triangle$ \\
\hline 20 & $\times$ & $\times$ & 0 & 0 & 0 & 0 \\
\hline 30 & $\times$ & $\times$ & 0 & 0 & 0 & 0 \\
\hline 40 & $x$ & $x$ & 0 & 0 & 0 & 0 \\
\hline 50 & $\times$ & $\times$ & 0 & $\times$ & 0 & $\times$ \\
\hline 60 & 0 & 0 & $x$ & $x$ & 0 & 0 \\
\hline 70 & 0 & 0 & $x$ & $\times$ & 0 & 0 \\
\hline 80 & 0 & 0 & $x$ & $x$ & 0 & 0 \\
\hline 90 & 0 & 0 & $x$ & $x$ & 0 & 0 \\
\hline 100 & 0 & $\times$ & $x$ & $x$ & 0 & $\triangle$ \\
\hline 110 & 0 & $\times$ & $x$ & $x$ & 0 & $\triangle$ \\
\hline 120 & 0 & $x$ & $x$ & $\triangle$ & 0 & $x$ \\
\hline 130 & 0 & $x$ & $x$ & $\triangle$ & $\triangle$ & 0 \\
\hline 140 & $\triangle$ & $x$ & $x$ & 0 & $\triangle$ & 0 \\
\hline 150 & $\triangle$ & $\times$ & $x$ & 0 & $\triangle$ & 0 \\
\hline 160 & $\triangle$ & $x$ & $x$ & 0 & $\triangle$ & 0 \\
\hline 170 & $\triangle$ & $x$ & $x$ & $\times$ & $\triangle$ & $x$ \\
\hline 180 & $\triangle$ & $x$ & $x$ & $x$ & $\times$ & $x$ \\
\hline 190 & $\times$ & $x$ & $x$ & $x$ & $\triangle$ & $x$ \\
\hline 200 & $\times$ & $\times$ & $x$ & $\times$ & $\triangle$ & $x$ \\
\hline & \multicolumn{3}{|c|}{$\begin{array}{l}\text { Toward free-end side } \\
\text { Toward fixed-end side }\end{array}$} & \multicolumn{3}{|c|}{$\begin{array}{l}\text { : Move to the other side } \\
\triangle: \text { Stop before end side } \\
\quad \times \text { : No movement }\end{array}$} \\
\hline
\end{tabular}

Here, in order to clarify the phenomenon of change in the movement of the proof mass with the input frequency, we considered the relationship between the tendency for proof mass movement and tip displacement. Tables 4 and 5 list the relationship between the tendency for proof mass movement and tip displacement of Types 1 and 2. From Table 4, we can observe that when the tip displacement exceeds $0.17 \mathrm{~mm}$, the proof mass moves to the fixed-end side. Conversely, when the tip displacement is between $0.045 \mathrm{~mm}$ and $0.17 \mathrm{~mm}$, the proof mass moves to the free-end side, and when it is less than $0.045 \mathrm{~mm}$, the proof mass does not move. From Table 5, we can observe that when the tip displacement exceeds $0.06 \mathrm{~mm}$, the proof mass moves to the fixed-end side. Conversely, when the tip displacement is between $0.045 \mathrm{~mm}$ and $0.06 \mathrm{~mm}$, the proof mass moves to the free-end side, and when it is less than $0.045 \mathrm{~mm}$, the proof mass does not move. It is interesting to note that the border of tip displacement that determines the direction of proof mass movement differs depending on the proof mass type. 
In addition, there a threshold tip displacement exists for start the process, regardless of the weight of the proof mass. Therefore, we considered the physical phenomenon of the movement by observing the proof mass under a high-speed microscope. In either movement, the proof mass moved like an inchworm, or a looper-a type of caterpillar. The proof mass was driven by two mechanisms, namely, a nut swung like a pendulum, which hauled itself by the friction between the upper surface of the cantilever and screw head. In addition, the imperceptible inclination of the screw head to the direction of movement was recognized. We also considered the cases where the proof mass stopped on the way and where the proof mass hopped on the site. The impact of a cantilever is generated by swinging the nut, and it causes an increase in the output voltage.

Table 4. Relationship between (a) Tip displacement and (b) Movement of the proof mass corresponding to input frequency (Type 1).

\begin{tabular}{|c|c|c|c|c|c|}
\hline \multirow[b]{3}{*}{$f(\mathrm{~Hz})$} & \multicolumn{2}{|l|}{ (a) } & \multicolumn{3}{|c|}{ (b) } \\
\hline & Case 2 & Case 3 & \multirow[b]{2}{*}{$f(\mathrm{~Hz})$} & \multicolumn{2}{|c|}{ Starting Position } \\
\hline & \multicolumn{2}{|c|}{$u_{\text {tip }}(\mathrm{mm})$} & & Fixed-End Side $(z=32 \mathrm{~mm})$ & Free-End Side $(z=56 \mathrm{~mm})$ \\
\hline 10 & 2.745 & 2.782 & 10 & $\times$ & 0 \\
\hline 20 & 0.645 & 0.684 & 20 & $x$ & 0 \\
\hline 30 & 0.330 & 0.368 & 30 & $x$ & 0 \\
\hline 40 & 0.233 & 0.301 & 40 & $x$ & 0 \\
\hline 50 & 0.222 & 0.188 & 50 & $x$ & 0 \\
\hline 60 & 0.039 & 0.041 & 60 & 0 & $x$ \\
\hline 70 & 0.047 & 0.059 & 70 & 0 & $x$ \\
\hline 80 & 0.048 & 0.072 & 80 & 0 & $x$ \\
\hline 90 & 0.048 & 0.086 & 90 & 0 & $x$ \\
\hline 100 & 0.050 & 0.378 & 100 & 0 & $x$ \\
\hline 110 & 0.049 & 0.124 & 110 & 0 & $x$ \\
\hline 120 & 0.051 & 0.074 & 120 & 0 & $x$ \\
\hline 130 & 0.061 & 0.061 & 130 & 0 & $x$ \\
\hline 140 & 0.085 & 0.043 & 140 & $\triangle$ & $x$ \\
\hline 150 & 0.164 & 0.039 & 150 & $\triangle$ & $x$ \\
\hline 160 & 0.156 & 0.042 & 160 & $\triangle$ & $x$ \\
\hline 170 & 0.080 & 0.034 & 170 & $\triangle$ & $x$ \\
\hline 180 & 0.058 & 0.037 & 180 & $\triangle$ & $x$ \\
\hline 190 & 0.041 & 0.034 & 190 & $\times$ & $x$ \\
\hline \multirow[t]{5}{*}{200} & 0.030 & 0.034 & 200 & $\times$ & $x$ \\
\hline & \multirow{3}{*}{\multicolumn{2}{|c|}{$\begin{array}{c}0.17 \mathrm{~mm} \sim \\
0.045 \sim 0.17 \mathrm{~mm} \\
\sim 0.045 \mathrm{~mm}\end{array}$}} & \\
\hline & & & \multirow{2}{*}{\multicolumn{3}{|c|}{$\triangle:$ Stop before end side }} \\
\hline & & & $\times:$ No movement & & \\
\hline & & & \multicolumn{3}{|c|}{$\begin{array}{l}\text { Toward free-end side } \\
\text { Toward fixed-end side }\end{array}$} \\
\hline
\end{tabular}

Table 5. Relationship between (a) Tip displacement and (b) Movement of the proof mass corresponding to input frequency (Type 2).

\begin{tabular}{|c|c|c|c|c|c|}
\hline \multirow[b]{3}{*}{$f(\mathrm{~Hz})$} & \multicolumn{2}{|l|}{ (a) } & \multirow[b]{3}{*}{$f(\mathrm{~Hz})$} & \multicolumn{2}{|l|}{ (b) } \\
\hline & Case 2 & Case 3 & & \multicolumn{2}{|c|}{ Starting Position } \\
\hline & \multicolumn{2}{|c|}{$u_{\text {tip }}(\mathrm{mm})$} & & Fixed-End Side $(z=32 \mathrm{~mm})$ & Free-End Side $(z=56 \mathrm{~mm})$ \\
\hline 10 & 2.697 & 2.690 & 10 & $\times$ & $\times$ \\
\hline 20 & 0.658 & 0.678 & 20 & $x$ & 0 \\
\hline 30 & 0.349 & 0.363 & 30 & $x$ & 0 \\
\hline 40 & 0.240 & 0.250 & 40 & $x$ & 0 \\
\hline 50 & 0.277 & 0.266 & 50 & $x$ & $x$ \\
\hline
\end{tabular}


Table 5. Cont.

\begin{tabular}{|c|c|c|c|c|c|}
\hline \multirow[b]{3}{*}{$f(\mathrm{~Hz})$} & \multicolumn{2}{|l|}{ (a) } & \multirow[b]{3}{*}{$f(\mathrm{~Hz})$} & \multicolumn{2}{|l|}{ (b) } \\
\hline & Case 2 & Case 3 & & \multicolumn{2}{|c|}{ Starting Position } \\
\hline & \multicolumn{2}{|c|}{$u_{\text {tip }}(\mathrm{mm})$} & & Fixed-End Side $(z=32 \mathrm{~mm})$ & Free-End Side $(z=56 \mathrm{~mm})$ \\
\hline 60 & 0.047 & 0.045 & 60 & 0 & $\times$ \\
\hline 70 & 0.054 & 0.051 & 70 & 0 & $\times$ \\
\hline 80 & 0.059 & 0.056 & 80 & 0 & $\times$ \\
\hline 90 & 0.048 & 0.056 & 90 & 0 & $\times$ \\
\hline 100 & 0.051 & 0.058 & 100 & $\times$ & $\times$ \\
\hline 110 & 0.055 & 0.070 & 110 & $\times$ & $\times$ \\
\hline 120 & 0.059 & 0.118 & 120 & $x$ & $\triangle$ \\
\hline 130 & 0.060 & 0.456 & 130 & $x$ & $\triangle$ \\
\hline 140 & 0.057 & 0.099 & 140 & $\times$ & 0 \\
\hline 150 & 0.078 & 0.061 & 150 & $\times$ & $\bigcirc$ \\
\hline 160 & 0.137 & 0.044 & 160 & $x$ & 0 \\
\hline 170 & 0.166 & 0.040 & 170 & $x$ & $\times$ \\
\hline 180 & 0.058 & 0.032 & 180 & $x$ & $\times$ \\
\hline 190 & 0.047 & 0.026 & 190 & $x$ & $x$ \\
\hline \multirow[t]{3}{*}{200} & 0.038 & 0.026 & 200 & $\times$ & $\times$ \\
\hline & \multirow{2}{*}{\multicolumn{2}{|c|}{$\begin{array}{c}0.06 \mathrm{~mm} \sim \\
0.045 \sim 0.06 \mathrm{~mm} \\
\sim 0.045 \mathrm{~mm} \\
\end{array}$}} & \multicolumn{3}{|c|}{$\begin{array}{l}\bigcirc: \text { Move to the other side } \\
\triangle: \text { Stop before end side } \\
\quad \times: \text { No movement }\end{array}$} \\
\hline & & & & \multicolumn{2}{|c|}{$\begin{array}{l}\text { Toward free-end side } \\
\text { Toward fixed-end side }\end{array}$} \\
\hline
\end{tabular}

\section{Conclusions}

A numerical and experimental evaluation of an energy harvesting device with resonant tuning was conducted, and the influence of weight on the resonant-tuning function was considered. The resonant frequency was found to depend on the weight and location of the movable proof mass. The trend of proof mass movement depended on the input frequency and correlated with tip displacement. In addition, the movement range and difference in tendency depended on the weight of the proof mass. For both the used weight types, at near resonant frequency, the movable proof mass stayed in a steady position or moved to an end side. However, regardless of the weight type, the output voltage increased with proof mass movement. This study may be helpful in designing progressive vibration energy harvesting devices that do not require external power to adjust their resonant frequency to the input vibration. In addition, self-tuning mechanisms using a moving proof mass are easy to combine with other wideband mechanisms (such as, using a magnet or stopper) also. Future work on self-tuning mechanisms will involve extensive inspections of the factors that initiate the movement of the proof mass and its effect on output power.

Author Contributions: Kotaro Mori conceived, designed the experiments, and wrote the paper; Tadashi Horibe conceived the experiments; Shigekazu Ishikawa performed the experiments and simulations.

Conflicts of Interest: The authors declare no conflict of interest.

\section{References}

1. Bozorth, R.M. Ferromagnetism; IEEE: New York, NY, USA, 1993.

2. Engdahl, G. Handbook of Giant Magnetostrictive Materials; Academic: San Diego, CA, USA, 2000.

3. Yang, Z.; Nakajima, K.; Onodera, R.; Tayama, T.; Chiba, D.; Narita, F. Magnetostrictive clad steel plates for high-Performance vibration energy harvesting. Appl. Phys. Lett. 2018, in press. [CrossRef]

4. Narita, F; Katabira, K. Stress-rate dependent output voltage for $\mathrm{Fe}_{29} \mathrm{Co}_{71}$ magnetostrictive fiber/polymer composites: fabrication, experimental observation and theoretical prediction. Mater. Trans. 2017, 58, 302-304. [CrossRef]

5. Narita, F. Inverse magnetostrictive effect in $\mathrm{Fe}_{29} \mathrm{Co}_{71}$ wire/polymer composites. Adv. Eng. Mater. 2017, 19, 1600586. [CrossRef] 
6. Zhao, X.; Lord, D.G. Application of the Villari effect to electric power harvesting. J. Appl. Phys. 2006, 99, 08M703. [CrossRef]

7. Hu, J.; Xu, F.; Huang, A.Q.; Yuan, F.G. Optimal design of a vibration-based energy harvester using magnetostrictive material (MsM). Smart Mater. Struct. 2011, 20, 015021. [CrossRef]

8. Peigney, M.; Siegert, D. Piezoelectric energy harvesting from traffic-induced bridge vibrations. Smart Mater. Struct. 2013, 22, 095019. [CrossRef]

9. Narita, F.; Fox, M. A review on piezoelectric, magnetostrictive, and magnetoelectric materials and device technologies for energy harvesting applications. Adv. Eng. Mater. 2018, 20, 1700743. [CrossRef]

10. Holistic. Next Generation Energy-Harvesting Electronics. Available online: http://www.holistic.ecs.soton. ac.uk/ (accessed on 15 March 2018).

11. Lallart, M.; Anton, S.R.; Inman, D.J. Frequency self-tuning scheme for broadband vibration energy harvesting. J. Intell. Mater. Syst. Struct. 2010, 21, 897-906. [CrossRef]

12. Shindo, Y.; Narita, F. Dynamic bending/torsion and output power of S-shaped piezoelectric energy harvesters. Int. J. Mech. Mater. Des. 2014, 10, 305-311. [CrossRef]

13. Firoozy, P.; Khadem, S.K.; Pourkiaee, S.M. Broadband energy harvesting using nonlinear vibrations of a magnetopiezoelastic cantilever beam. Int. J. Eng. Sci. 2017, 111, 113-133. [CrossRef]

14. Miller, L.M.; Pillatsch, P.; Halvorsen, E.; Wright, P.K.; Yeatman, E.M.; Holmes, A.S. Experimental passive self-tuning behavior of a beam resonator with sliding proof mass. J. Sound Vibr. 2013, 332, 7142-7152. [CrossRef]

15. Mori, K.; Horibe, T.; Ishikawa, S.; Shindo, Y.; Narita, F. Characteristics of vibration energy harvesting using giant magnetostrictive cantilevers with resonant tuning. Smart Mater. Struct. 2015, 24, 125032. [CrossRef]

16. Alshits, V.I.; Darinskii, A.N.; Lothe, J. On the existence of surface waves in half-infinite anisotropic elastic media with piezoelectric and piezomagnetic properties. Wave Motion 1992, 16, 265-283. [CrossRef]

17. Wang, L.; Yuan, F.G. Vibration energy harvesting by magnetostrictive material. Smart Mater. Struct. 2008, 17, 045009. [CrossRef]

18. Nan, C.W.; Li, M.; Huang, J.H. Calculations of giant magnetoelectric effects in ferroic composites of rare-earth-iron alloys and ferroelectric polymers. Phys. Rev. B 2001, 63, 144415. [CrossRef]

(C) 2018 by the authors. Licensee MDPI, Basel, Switzerland. This article is an open access article distributed under the terms and conditions of the Creative Commons Attribution (CC BY) license (http:/ / creativecommons.org/licenses/by/4.0/). 